\section{Cost-effective or profligate community} psychiatry?'

\section{PETER TYRER}

In the past 30 years there has been a Gadarene rush towards community psychiatry in the developed world. Old psychiatric hospitals have been condemned as inefficient relics of a past age of unnecessary institutional care, those who require hospital in-patient treatment have become regarded increasingly as failures of community care and resources originally earmarked for institutional care have been transferred to new community developments. Although the psychiatric profession was instrumental in pointing out the many advantages of community psychiatry (Bennett, 1991) the initial phase of what can be called the de-instutionalisation of the mentally ill was carried out by stealth and was first highlighted by Tooth \& Brooke in their seminal paper of 1961. Although a healthy balance was achieved between clinicians, service planners and government policy during the 1960 s and 1970 s so that consensus was generally achieved in the reform of mental health services, the past 15 years have seen an acceleration of the process of devolution of psychiatric care which has been dominated by managers in a system that is now dominated by market forces. This movement has seemed to have developed a momentum of its own that is attracting increasing criticism (e.g. Coid, 1994) and at this stage it is appropriate to ask where we are going, and why.

Although at first the motives behind the push for more community care were clinical and sociological they now appear to be financial. Because so much of the budget for mental health services is devoted to in-patient provision, at a time of economic retrenchment new developments can seldom be funded from new money and it is natural for managers to look towards transferring funding from in-patient to community care. This option is particularly

I. Presented at a PRiSM conference on community care in psychiatry in February 1997 at Gatwick. UK. attractive when it may also lead to a large capital gain when a psychiatric hospital is finally sold. When challenged on these plans it is common for managers to repeat the mantra that the change to a more community-oriented service is 'more costeffective'. The evidence for this statement is worth examining closely as it is by the yardstick of economics that the policy now stands or falls.

\section{COSTS OF COMMUNITY CARE}

In randomised controlled trials of services which compare hospital-focused care and its community equivalents most studies report lower costs for the communityfocused services (Weisbrod et al, 1980; Hoult \& Reynolds, 1985; Muijen et al, 1992; Merson et al, 1996) but these studies almost always compare the costs of new teams with those of existing services and such comparisons may not always be an accurate reflection of actual costs in everyday practice (Tyrer et al, 1986). When other issues are taken into account, such as greater referral rates to community teams (Goldberg et al, 1996) and the costs of care for the very small group of patients who are most dependent on psychiatric services (Knapp, 1995) (who are often excluded from controlled trials either through selection or default) the cost advantages of community care become much less or disappear altogether. However, one common finding is that when what began as a daily living programme for the severely mentally ill (Stein \& Test, 1980), but which has become widely known as assertive community treatment, is applied, the costeffectiveness is improved, largely because patients spend shorter periods in hospital (Weisbrod et al, 1980). Such assertive treatment, also known as 'aggressive outreach', is a team-focused approach which makes determined efforts not only to stay in regular contact with patients but also to maintain them in treatment and improve their quality of life.

\section{DEVELOPMENT OF CASE AND CARE MANAGEMENT}

As community care has become the norm in psychiatric services the services provided for the mentally ill have also had to change. In the early years of the de-institutionalisation era these changes were led by providers within the service (MacMillan, 1963; Sainsbury et al, 1966; Freeman, 1983) and were generally successful. As the paths of managers and professionals have diverged in recent years the reforms have been instituted by managers and service planners without informed input from the mental health professions and have increasingly been driven by the need to achieve savings by closing beds. Rather late in the day it was appreciated that community care had one major handicap compared with hospital care; patients had less supervision and sometimes none at all. This led to the introduction of systems focused on the need to maintain contact with patients and to maintain a treatment plan across all the different settings of care (including in-patient care). This system is described as case management in the USA but, rather confusingly, is split between two new systems, care management and the Care Programme Approach (CPA) in England but not yet in the rest of the UK (Department of Health, 1993, 1996; Kingdon, 1994).

\section{REASONS FOR FAILURE OF CURRENT SYSTEM}

Despite the apparent face validity of this reform (no-one doubts that maintaining contact with, and care for, patients with severe mental illness is wise and constitutes good practice) it was introduced without adequate research of its effectiveness and cost, and the effect on the ground has sometimes been little short of disastrous. The system has relied on a single keyworker, backed up to a variable extent by community teams and by other agencies, acting as coordinator of care and chief contact for each patient, yet at the same time giving the responsible medical officer, usually the consultant psychiatrist, the ultimate responsibility for decisions or any disasters that may occur. Added to this is the disruptive combination of care management supplied 
by separate professionals (social workers) acting as purchasers, and care programming from other mental health professionals acting as providers, which sabotages efforts at creating integrated care.

This unwieldy dinosaur with its health and social care brains working independently is both expensive and ineffective. Keyworkers, particularly those with limited training (an issue which has only belatedly been addressed by hospital trusts implementing these reforms), may feel illequipped about taking on the main coordination of care, frequently develop burn-out (Lancet, 1994) and look for work in less stressful areas of mental health. The brokerage model of case management has increased admission to hospital by around $100 \%$ (Marshall et al, 1996) and the duration of admissions is also longer (Tyrer et al, 1995). At least some of the greater pressures on in-patient beds noted in cities such as London (MILMIS, 1995) can be explained by this unforeseen consequence of recent reforms. Many of these beds are occupied by patients who are waiting for placements through the new system and do not need in-patient facilities. When this reaches proportions of $30 \%$ or more (Fulop et al, 1996) the frustrations of practitioners overflow. Added to this is the disruption created by extra-contractual referrals (ECRs), which now might be redefined as extremely costly referrals, as the discontinuity of care created by admissions to another hospital almost doubles the costs of care through longer admissions and poor integration of care plans (Tyrer et al, 1997).

We are thus faced with two models of community care; a profligate model which is expensive, increases bed use and separates professionals, and a cost-effective one which is much cheaper, reduces bed use and promotes team work. The right choice is obvious and any observer taking a historical perspective of psychiatry in the last years of the 20th century would find it hard to explain why we have been so misled. There is a possible explanation. Those who have introduced the profligate model may have thought they were introducing the cost-effective one, but the distortions created by inadequate resources, inappropriate mix of skills, and inflexible statutory demands have undermined the main raison d'être of assertive treatment: flexible integrated teamwork by staff who work to a common agenda created by the needs of

PETER TYRER. Department of Psychiatry, Division of Neuroscience and Psychological Medicine. Imperial College School of Medicine. Paterson Centre. London W2 IPD

(First received 8 April 1997, final revision 24 July 1997, accepted 28 July 1997)

their patients. The research evidence has not been listened to, and its bowdlerised interpretation, embellished with new elements that have no evidence base, constitute the main reason for our present predicament.

\section{SOLUTION}

The way forward is clear. If community care is to be put on course again we need to promote the development of well-trained teams with common training and philosophies of care, to integrate the provision of hospital care and supported accommodation under a common administrative framework (probably through the health services), and ensure that any changes proposed are tested at the coal face of care before they are converted into policy. The paradox is that recent reforms implemented through market forces have failed primarily through market economics; they simply do not pay.

Fortunately there are signs that lessons have been learnt and already there are clear recommendations that will help to reverse the current trend; greater focus on service functions, more funding of what is misleadingly called 'social care' from health providers, and for all forms of care, including housing and employment, to be incorporated into plans for individual patients (King's Fund London Commission, 1997 , p. 140). Other countries could also benefit from examining the experience of the UK in the past 10 years, so that they can avoid the dangers of allowing their mental health workers to be led awry by directives derived distantly from clinical practice, which separate them from their core tasks and which ultimately undermine and emasculate their skills.

\section{ACKNOWLEDGEMENTS}

I thank Frank Holloway, David Kingdon and Martin Knapp for helpful discussions.

\section{REFERENCES}

Bonnett, D. (1991) Community Psychiatry: The Principles Edinburgh: Churchill Livingstone.

Cold, J. (1994) Failure in community care: psychiatry's dilemma. British Medical Journal, 308. 805-806.

Department of Health (1993) The Heolth of the Notion. Key Area Handbook: Mental IIIness. London: HMSO.

- (1996) Building Bridges: A Guide to Arrangements for Interagency Working for the Core and Protection of Severely Mentolly III People. London: Department of Health.

Freeman, H. (1983) Concepts of community psychiatry British journal of Hospital Medicine. 30, 90-96.

Fulop, N. J., Kofiman, J., Carson, S., et ol (1996) Use of acute psychiatric beds: a point prevalence survey in North and South Thames regions. Journal of Public Health Medicine, 18. 207-216.

Goldbers, D., Jackson, G., Gater, R., ex al (1996) The treatment of common mental disorders by a community team based in primary care: a cost-effectiveness study. Psychological Medicine, 26, 487-492.

Hoult, J. \& Roynolds, I. (1905) Schizophrenia: a comparative trial of community-oriented and hospital oriented psychiatric care. Acto Psychiotrico Scondinovico. 69. 359-372.

Kingdon, D. (1994) Care programme approach: recent government policy and legislation. Psychiatric Bulletin, 18. $68-70$.

King's Fund London Commission (1997) Transforming Health in London. London: King's Fund Publishing.

Knapp, M. (1995) Community mental health services: towards an understanding of cost-effectiveness. In Community Psychiatry in Action: Anolysis and Prospects (eds P. Tyrer \& F. Creed). Pp. III-145. Cambridge: Cambridge University Press.

Leneet (1994) Editorial: Burnished or burnt out: the delights and dangers of working in health. Lancet. 344. 1583-1584.

MacMillan, D. (1963) Recent developments in community mental health. Loncet, i, 567-571.

Marshall, M., Gray, A., Lockwood, A., et ol (1996)

Case management for people with severe mental disorders. In Schizophrenia Module of the Cochrone Dotobose of Systematic Reviews. The Cochrane Collaboration. Issue 3 (eds C. Adams. J. Anderson \& J. De Jesus Maris). London: BMJ Publishing.

Merson, S., Tyrer, P., Carlen, D., et al (1996) The cost of treatment of psychiatric emergencies: a comparison of hospital and community services. Psychological Medicine. 26. 727-734.

MILMIS Project Group (1995) Monitoring inner London mental illiness services. Psychiotric Bulletin, 19 276-280.

Muijen, M., Marks, I. M., Connolly, J., et al (1992) Home based care and standard hospital care for patients with severe mental illness: a randomised controlled trial. British Medical Journal, 304, 749-754. 
Sainsbury, P., Walk, D. \& Grad, J. (1966) Evaluating the Graylingwell Hospital community psychiatric service in Chichester. Milbank Memorial Fund Quorterly, 44. 243-245.

Stein, L. I. \& Test, M. A. (1980) Alternative to mental hospital treatment. I. Conceptual model, treatment program and clinical evaluation. Archives of General Psychiatry. 36, 1073-1079.
Tooth, G. C. \& Brooke, E. M. (1961) Trends in the mental hospital population and their effect on future planning. Loncet, i, 710-713.

Tyror, P., GIII, D. \& Farr, P. (1986) Cost of community psychiatry. British Journal of Psychiatry, 149, 795-796.

_, Morgan, J., Van Horn, E., ete al (1995) A randomised controlled study of close monitoring of vulnerable psychiatric patients. Loncet, 345, 756-759.
-, Evans, K., Gandhi, N., et al (1997) A randomised controlled trial of two models of care for discharged psychiatric patients: no advantage of better community care with insufficient hospital beds. British Medical Journal, in press.

Welsbrod, B. A., Test, M. A. \& Stain, L. I. (1980) Alternative to mental hospital treatment. II. Economic benefit-cost analysis. Archives of General Psychiatry, 37 400-405. 